\title{
Maximum Power Tracking System Based on Power Electronic Topology for Wind Energy Conversion System Applications
}

\author{
Musavir Hussain \\ Department of \\ Electrical Engineering, \\ Mehran University of \\ Engineering \& \\ Technology, \\ Jamshoro, Pakistan
}

\author{
Mazhar H. Baloch \\ Department of \\ Electrical Engineering, \\ Mehran University of \\ Engineering \& \\ Technology, \\ Jamshoro, Pakistan
}

\author{
Farhana Umer \\ Department of \\ Electrical Power \\ Engineering, \\ Islamia University of \\ Bahawalpur, \\ Bahawalpur, Pakistan
}

\author{
Abdul H. Memon \\ Department of \\ Electrical Engineering, \\ Mehran University of \\ Engineering \& \\ Technology, \\ Jamshoro, Pakistan
}

\author{
Noman K. Pathan \\ Department of \\ Electrical Engineering, \\ Mehran University of \\ Engineering \& \\ Technology, \\ Jamshoro, Pakistan
}

\begin{abstract}
Wind energy has emerged as a dominant alternative power generation source. Conventional energy resources are depleting and their increasing cost cannot be ignored. Wind energy has taken an important role in replacing fossil fuels and nuclear energy. However, optimal exploitation of wind energy systems has remained a thought-provoking problem due to the nonlinear behavior of the wind speed. Distribution generation system and isolated micro-grid (MG) are mainly used in a wind energy system in order to utilize maximum potential of wind through the maximum power tracking algorithm based on DCDC boost power electronic converter. In this paper, authors propose a technique which is effectively workable, highly reliable, of low cost and induces less mechanical stress on the wind generator system (WGS). Experimental results of the proposed system verify that the effectiveness near optimal WGS output power increased approximately up to $50 \%$. Thus, better exploitation of the available wind power is obtained under low wind speeds.
\end{abstract}

Keywords-boost converter; maximum power tracker system (MPTS); variable speed; wind-generator system (WGS)

\section{INTRODUCTION}

There is a continuous rise in power demand. Additional cost is required to control and minimize resultant environmental pollution due to conventional energy production methods. This has stimulated the exploit of non-conventional energy resources. Wind energy is the most prevailing and dominant source of energy among all non-conventional energy resources. Being pollution free, endless and very cheap source for power generation, it is rapidly gaining popularity [1]. In Pakistan and Malaysia research has been conducted in renewable energy systems, consisting of feasibility studies in renewable energy utilization [2-5]. Figure 1 depicts the global cumulative installed capacity of wind energy and Figure 2 depicts the annual installed capacity of wind energy from 2001 to 2017. The trend clearly depicts that it will increase in the future. Region wise wind power installed capacity is depicted in Figure 3 with Asia on the top [6-8]. Optimal exploitation of wind energy systems has remained a challenging problem over the last decades. Generally, power generated from wind turbine systems is not at optimal level due to the nonlinear behavior of the wind speed. The output power of wind energy system depends upon wind speed and wind speed varies throughout the day, hence it is a challenging task for the power engineer to track maximum power output from the wind turbine for all wind speed conditions. Hence, it is conducive to propose a based on experiment algorithm that can track maximum power under variable speed. Many researchers develop their model and simulate their proposed algorithm before real implementation. Modeling and simulation also provide effective ways of analyzing different parameter associated with the wind energy conversion system. But to understand the nonlinear behavior of wind turbine, real time study is the best choice.

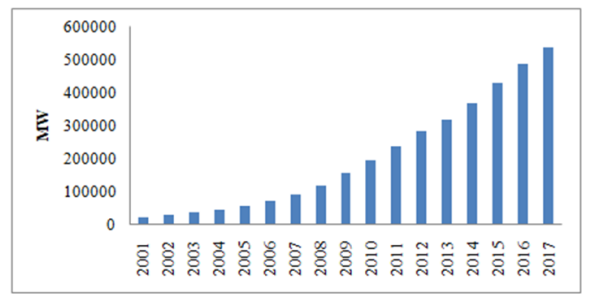

Fig. 1. Commulative globally installed wind energy in MW

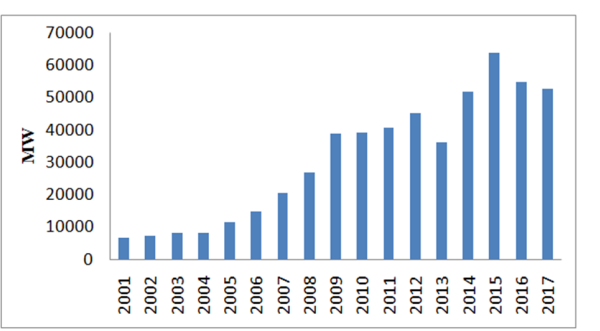

Fig. 2. Annual globally installed wind energy in MW. 


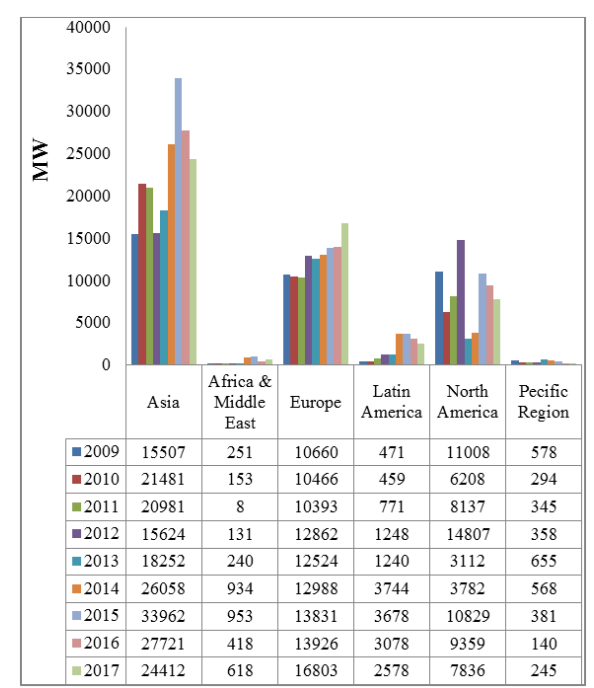

Fig. 3. Region-wise installed capacity of wind energy in MW.

MPPT (maximum power point tracker), also known as power point tracker (PPT), is a technique commonly utilized for wind energy systems to optimize the output power under variable speed. However, wind turbines are controlled, in order to operate in a particular array. A wind turbine operates in four different zones $[9,10]$. Zone-I is a zero power area where wind speed is too low to generate electrical power. Zone-II, lies between cut-in and rated speed. In this zone, the generator runs under-rated power. In Zone-III, the output power is controlled by the turbine. This happens when wind motion is sufficient for the wind turbine to reach its rated output power. Zone-IV is during stronger winds, where the wind power is so much that it could be unfavorable to the wind turbine, consequently the turbine will shut down [10].

\section{MAXIMUM POWER TRACKING TECHNIQUES}

\section{A. Power Signal Feedback}

Power signal feedback (PSF) technique is based on speedsensor less power signal feedback algorithm and has many advantages compared to others used for MPPT. In this MPPT technique, it is necessary to know the basic training of optimal curve in order to search optimal power. Many studies discussed that PSF is better than OTC, because the optimal power curve needs to be obtained through simulations/off line experiments on individual wind turbines and the reference power signal is produced through a recorded power curve or mechanical power formula [11-13]. The basic block diagram of PSF is depicted in Figure 4. PSF method uses a reference power which is maximum power at that particular wind speed. This presents an issue, as the prior knowledge of the wind turbine characteristics and wind speed measurements is required [13].

\section{B. Tip Speed Ratio Technique}

Tip Speed Ratio (TSR) MPPT technique is a simple technique because wind motion is directly and uninterruptedly estimated and can be calculated analytically and experimentally [13-15]. The finest TSR for a specified wind turbine is fixed independently from wind speed. However, wind speed is measured for achieving optimal rotor speed via optimum tip speed level as shown in Figure 5. The estimation technique is based on support vector regression, where inputs to the wind speed approximate are power and rotational speed of the wind turbine [14-15].

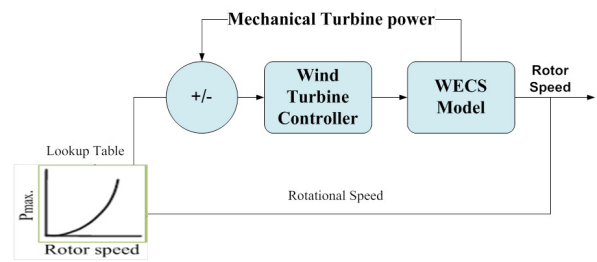

Fig. 4. Basic block diagram of PSF.

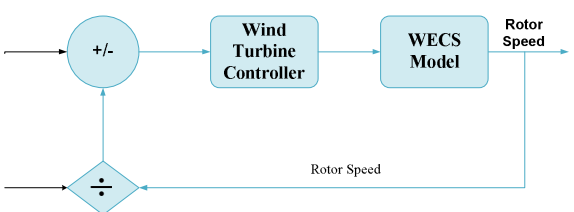

Fig. 5. Basic block diagram of TSR.

TSR control offers good performance with fast response and high efficiency. However, continuous precise wind speed measurements are not possible in reality. An accurate anemometer is expensive and adds extra cost to the system [13].

\section{Optimal Torque Control Technique}

Its block diagram is visualized in Figure 6. The basic principle of this technique is to regulate the electrical generator torque at optimal power reference torque of the desired wind speed of the wind turbine system.

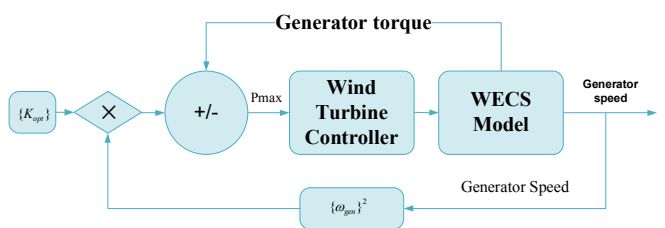

Fig. 6. Basic block diagram of optimal torque control technique.

Turbine power can be expected as a function of tip speed ratio and turbine speed [15-18]. Therefore, optimal torque equation can be written as follows in order to obtain the wind speed. We know that:

$$
\begin{aligned}
& P_{t_{-} o p t}=\frac{1}{2 \lambda_{c}^{3}} \pi \rho R^{5} \omega_{t}^{3} C_{p_{-} o p t} ; T_{t_{-} o p t}=P_{t_{-} o p t} \frac{1}{\omega_{t}}, \\
& T_{t_{-} o p t}=\frac{1}{2 \lambda_{c}^{3}} \pi \rho R^{5} C_{p_{-} o p t} \omega_{t}^{2}=k_{o p t} \omega_{t}^{2} ; \\
& k_{o p t}=\frac{1}{2 \lambda_{c}^{3}} \pi \rho R^{5} \omega_{t}^{2} C_{p_{-} o p t},
\end{aligned}
$$

where (2) is the analytical expression of the optimal torque curve, and can be used as a mechanical torque control. Authors 
in [19] reported that there is no big difference between power signal MPPT \& OTC MPPT controller regarding performances and complexities. In reality, the optimal torque control technique is efficient, rapid in operation and easy to construct. OTC does not directly estimate the wind speed, that's why its efficiency is lower compared to that of TSR [17].

\section{Summary}

The above mentioned techniques have some limitations, e.g. they require expensive devices like anemometers, which add extra cost to the system and they also require advanced knowledge of wind turbine characteristics. Our major aim is to seek an optimum tracker for a variable speed wind energy conversion system application which does not require advanced knowledge of the wind turbine characteristics or expensive devices for wind speed measurement. This paper compiles and investigates optimal tracking control algorithms, particularly squirrel cage induction machine (SCIM) based on its configuration model.

\section{WIND GENERATOR MODEL CHARACTERISTICS}

The power produced at the impact area on the turbine is expressed as [21, 27, 30, 31]:

$$
P_{w}=0.5 \rho \pi C_{p}(\lambda, \beta) R^{2} V_{\omega}^{3}
$$

where $\rho=1.25 \mathrm{~kg} / \mathrm{m}^{3}$ is the wind density, $R$ is the length of the turbine blade, $V_{\omega}$ is the wind speed, $C_{p}=0.3-0.59$ is the coefficient of power, $\beta$ is the pitch angle (in degrees) assuming zero degrees for Zone-II, $\lambda$ is the tip speed ratio and can be described as:

$$
\lambda=\frac{\omega R}{V_{\omega}}
$$

where $\omega$ is the wind generator rotor speed (in $\mathrm{rad} / \mathrm{sec}$ ). The turbine power relations with the wind power are defined as:

$$
\begin{aligned}
& P_{t}=T_{t} \omega_{t}==C_{p}(\lambda, \beta) P_{w} \\
& C_{p}=(0.73) 151 \frac{1}{R \omega_{t}} V_{\omega}-13.635 \mathrm{e}\left(\frac{1}{R \omega_{t}} V_{\omega}-0.003\right)^{-1}
\end{aligned}
$$

From (4) to (7), the turbine power of the wind generator captured by the wind turbine system is described by the wind speed and wind turbine speed can be defined as [22-31]:

$$
P_{t}=55.155 \rho A \frac{V_{\omega}}{R \omega_{t}}-0.09 \exp \left(\frac{V_{\omega}}{R \omega_{t}}-0.003\right)^{-1}
$$

From (8), the wind turbine power versus wind turbine speed is shown in Figure 7. It is observed that turbine power varies with respect to turbine speed at different wind speeds. From Figure 7 , we see that maximum power moves on a $3^{\text {rd }}$ order curve, which illustrates the maximum power produced by the wind turbine at each wind speed.

\section{CONTROLLER DESIGN FOR WIND GENERATOR SYSTEM}

A grid connected wind power system circuit diagram before booster is shown in Figure 8. The back electromagnetic force of the wind-generator system consists of a 3-phase sinusoidal voltage which is inverted to dc-voltage $\left(V_{\text {in }}\right)$ through a rectifier. In this study, our main intension on maximum power tracking control is performed by regulating the duty cycle of the DC-DC boost converted to the DC side. DC-DC equivalent circuit diagram for the generator control is shown in Figure 10. The DC-DC boost converter adjusts $\left(V_{i n}\right)$ through current/voltage control, and the dc-link voltage $\left(V_{d c}\right)$ is controlled through an inverter on grid side converter (GSC).

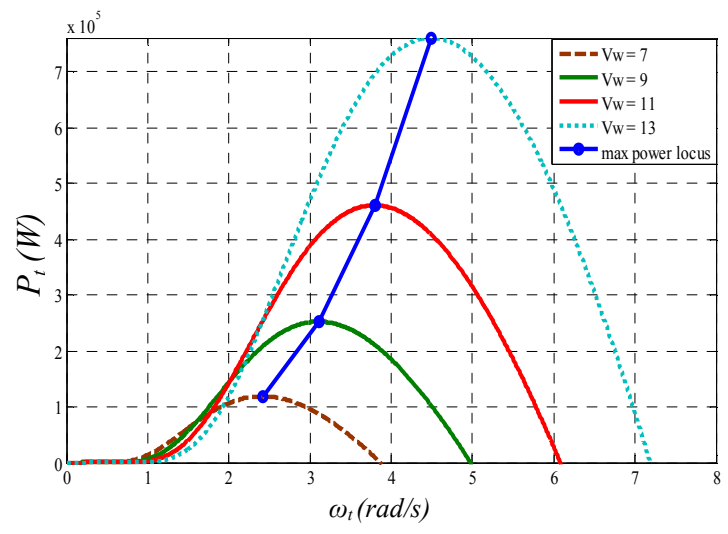

Fig. 7. Power versus turbine speed at different wind speeds.

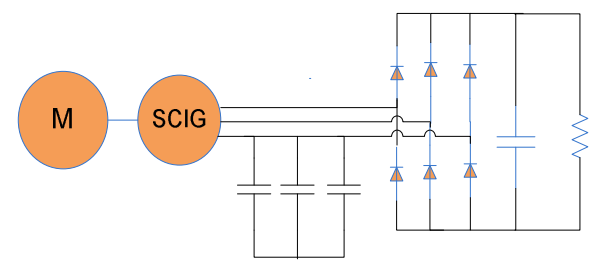

Fig. 8. Circuit diagram without booster.

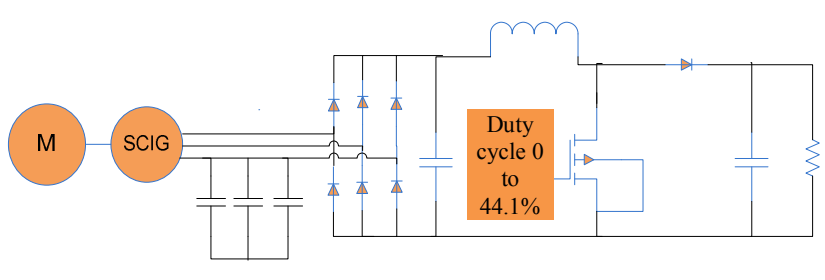

Fig. 9. Circuit diagram with booster.

\section{PROPOSED MPPT TECHNIQUE}

The proposed technique uses duty cycle as control variable to vary the generator speed with respect to turbine in the same proportion. This technique is basically based on the topology of power electronics which vary the duty cycle according to the measurement of output power taken successively and compare it with previous obtained result. The major problem of tracking the output power with the help of power electronic converter using duty cycle as a control variable, is effectively resolving the abrupt climb technique [32]. The technique is quite simple, independent and flexible, and does not need prior knowledge of wind turbine characteristics and expensive devices for speed measurement. 


\section{EXPERIMENTAL SET UP AND DISCUSSION}

For real time study of WECS, a wind tunnel is required, which is usually built to generate artificial controlled wind speed to run a wind energy conversion system. However, it is costly and space demanding. A software simulator is simple but it has many restrictions on real time analysis. A good solution is to emulate the wind turbine characteristic using a motor generator (MG)-set, in which the motor is run and controlled to reproduce the wind turbine profile under variable wind speeds. Through comprehensive study, a MG-set is employed as a model of the wind energy conversion system based on completely experimental setup. The machine used for power generation is SCIM. Permanent magnet DC machine is used as wind turbine emulator to analyze the non-linear behavior of wind turbine. In this application, a motor is operated at variable speed to analyze the output power of squirrel cage induction generator without and with DC-DC booster. Our main goal is to analyze the importance of maximum power point tracking in variable speed conditions. Figure 10 shows the experimental setup assembled on basis of DC-DC boost converter as discussed above.

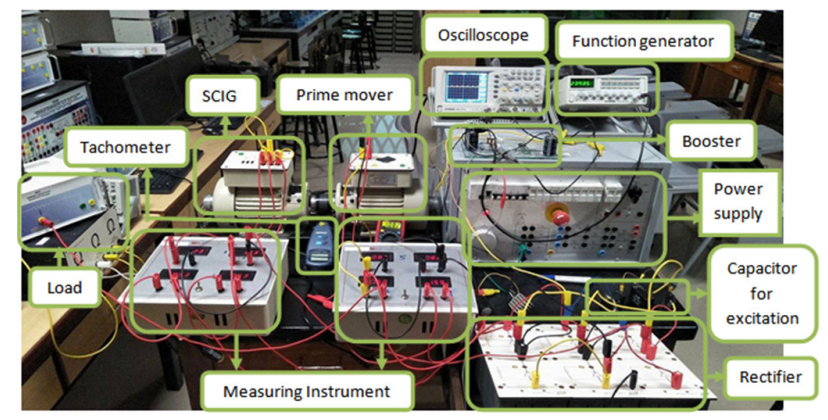

Fig. 10. Experimental set up desk for maximum power tracking system.

Initially, wind enrgy system was operated without DC-DC booster connected to the rectified output of the squirrel cage induction generator to analyze the output parameters like voltage, current, power under variable speed conditions. A resistive load was used as dummy load to take successive power measurements to analyze the generator output. To analyze the importance of power point tracking, the rectified output of the wind generator system was fed to the DC-DC booster consisting of one MOSFET and the calculated capacitor values from primary to secondary are $235 \mu \mathrm{f}, 900 \mathrm{~V}$ and $470 \mu f, 450 \mathrm{~V}$ respectively. The output inductor rated value is $1.8 \mathrm{mH}, 2.5 \mathrm{~A}$, having switching frequency around $240 \mathrm{kHz}$ (Table I). The effectiveness of the system response of the proposed MPTS control strategy based on DC-DC boost converter by varying duty cycle was confirmed.

\section{EXPERIMENTAL RESULTS AND DISCUSSION}

Through the experimental setup, results were obtained by varying the prime mover speed at different time durations in order to analyze the output of the wind-turbine system considering the squirrel cage induction generator. Prime mover is a PMDC permanent magnet direct current motor which acts as wind turbine emulator. Squirrel cage induction generator is coupled with wind turbine emulator and runs at variable speed.
TABLE I. EQUIPMENT LIST AND DISCRIPTION

\begin{tabular}{|c|c|}
\hline Name of Equipment & Discription with Model No \\
\hline $\begin{array}{c}\text { Prime Mover (DC permanent } \\
\text { magnet machine) }\end{array}$ & $\begin{array}{c}\text { 180Vdc, } 2.7 \mathrm{~A}, 0.4 \mathrm{KW}, 2500 \mathrm{rpm} . \text { Type: } \\
\text { EM-3330-1A, S/N: 201 }\end{array}$ \\
\hline $\begin{array}{c}\text { 3 Phase Squirrel Motor } \\
\text { (SCIG) }\end{array}$ & $\begin{array}{c}\text { 3-Phase, 220V,1.4A, 50/60Hz, 0.3KW, } \\
\text { Type:EM-3330-3C S/N: } 201\end{array}$ \\
\hline Tachometer & Tachometer 20713A \\
\hline Rectifier (for 3phase) & PE-5310-5A \\
\hline Measuring instrument & $1-1000 \Omega$ 500W \\
\hline Load (Resistor) & 15 uf $\pm 5 \%, 350-400 \mathrm{VAC}$ \\
\hline Capacitor (excitation cap) & Power Electronics Universal Supply \\
\hline Power Supply & Capacitor : 470uf $450 \mathrm{v} * 3$ \\
\hline & Inductor: $1.8 \mathrm{mH} 5 \mathrm{~A}$ \\
Booster & Diode: P600J \\
\hline Function generator & GWInstek GDS-1062A, 60Mhz \\
\hline Digital oscilloscope &
\end{tabular}

Parameters related to wind energy conversion system like speed, current, voltage and power were observed without any tracking technique applied to the wind generator system output and with the proposed technique applied to it. Squirrel cage induction generator operated at various speed conditions and its output power was analyzed either at different time durations or at regular intervals. Speed response is shown in Figure 11, which shows that generator output power varies with generator speed. It can be seen that at first the generator operated at $1110 \mathrm{rpm}$ and the power output was almost less than $10 \mathrm{~W}$. When speed varied from $1110 \mathrm{rpm}$ to $1130 \mathrm{rpm}$, observed power at output was almost 20W. From 1130rpm to 1140rpm the observed power was between $40 \mathrm{~W}$ and $50 \mathrm{~W}$. With further increase in speed, the output power increased and vice versa.

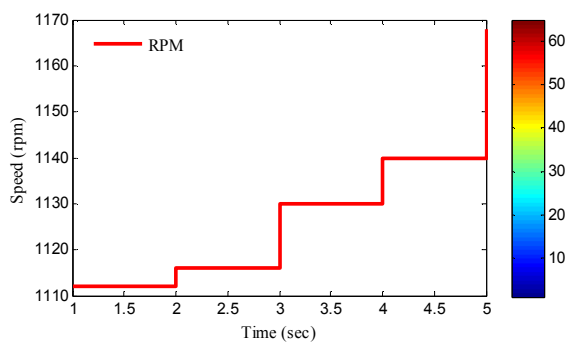

Fig. 11. Power response with varying rpm.

In this research study, our major intention was to extract the maximum power under varying speed of the prime mover. This application basically uses duty cycle as control variable to vary the generator speed with respect to wind turbine. In the proposed system, duty cycle varies with the help of pulse width modulation on the pulse applied to the gate of the MOSFET used in DC-DC booster. Speed and duty cycle vary and the generator output is observed so that power can be maximized by changing the point of energy conversion. In this application, the duty cycle of MOSFET used in the DC-DC booster varied from $20 \%$ to $44.1 \%$. The cumulative response of duty cycle at different timings can be shown in Figure 12.

One of the main objectives of this research was to analyze the importance of the maximum power tracking technique 
applied at the rectified output of the squirrel cage induction generator. The rectified output was analyzed by successive power measurements. Figure 13 shows the response of power without booster at different time durations. The maximum output from the generator is $42.67 \mathrm{~W}$ at $1170 \mathrm{rpm}$ without booster connect at the output. The squirrel cage induction generator is coupled with wind turbine emulator, runs at variable speed, and parameters related to wind energy conversion system like speed, current, voltage were observed without and with booster. It was found that current and voltage increased/boosted individually. In the power response without booster we found that maximum output power of the generator was $42.67 \mathrm{~W}$ at almost $1170 \mathrm{rpm}$. When we applied this rectified output to booster, it was also changed in the same proportion. At $1170 \mathrm{rpm}$ duty cycle changed by $44.1 \%$ and the output power with booster was $69.08 \mathrm{~W}$. Power response at different time durations with booster can be seen in Figure 14 . Maximum output power with booster was $69.08 \mathrm{~W}$ which is greater in comparison to the one without booster.

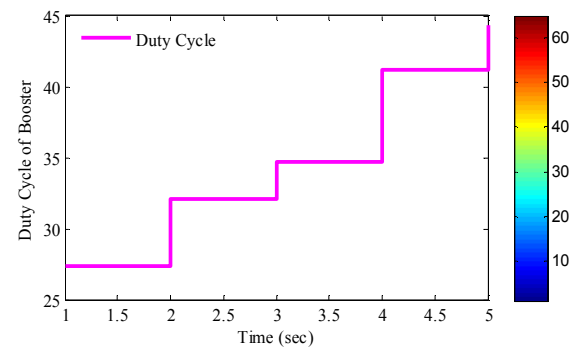

Fig. 12. Power response with varying duty cycle.

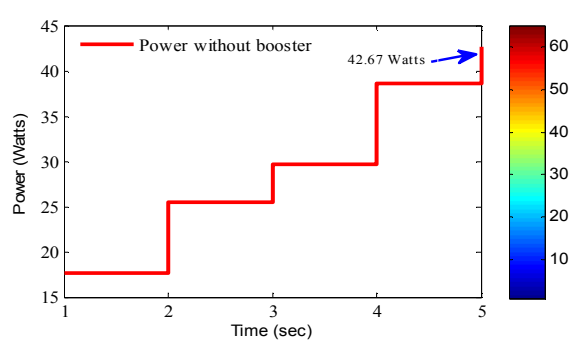

Fig. 13. Power response without booster.

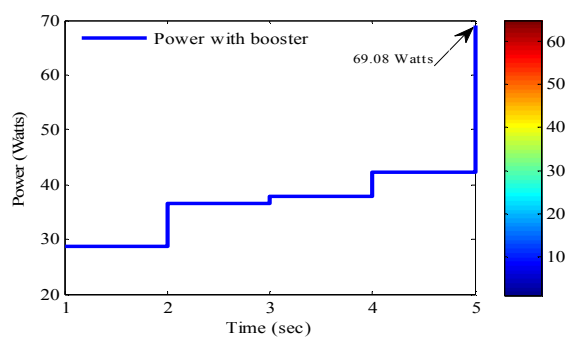

Fig. 14. Power response with booster.

\section{CONCLUSIONS}

In this paper, a prototype experimental model was developed for a maximum power tracking system with a step- up DC-DC power converter. The advantages of the proposed MTPS technique are: No prior knowledge is required for maximum power characteristics and wind speed. The wind turbine system operates at varying speed, so WGS takes minimum stress on a varying factor as the shaft/gear system. The proposed MTPS is dependent neither on wind speed and rotor speed rating of the wind generator system nor on the capacity of the DC-DC boost converter. The experimental results of the proposed model represent the output power generated by the wind generator system. They verify that WGS maximum power at the grid side is around $20 \%$ to $50 \%$ larger by varying duty cycle than when with directly connected with the rectifier. The proposed system utilizes more effectively the existing wind energy, in particular in the minimum wind speed region.

\section{ACKNOWLEDGMENT}

Authors wish to acknowledge the support regarding the research of the Start-Up Research Grant HEC Pakistan, under Grant No. 1652.

\begin{tabular}{ll} 
& \multicolumn{1}{c}{ APPENDIX } \\
& ACRONYMS \\
WGS & Wind Generator System \\
WECS & Wind Energy Conversion System \\
SCIG & Squirrel Cage Induction Generator \\
DC & Direct Current \\
MPPT & Maximum Power Point Tracking \\
MPTS & Maximum Power Tracking system \\
MOSFET & Metal Oxide Semiconductor Field Effect Transistor \\
TSR & Tip Speed Ratio \\
OLT & Optimal Load Torque \\
PSF & Power Signal Feedback
\end{tabular}

\section{REFERENCES}

[1] R. Saidur, M. R. Islam, N. A. Rahim, K. H. Solangi, “A review on global wind energy policy", Renewable and Sustainable Energy Reviews, Vol. 14, No. 7, pp. 1744-1762, 2010

[2] M. H. Baloch, G. S. Kaloi, J. Wang. "Feasible Wind Power Potential from Costal Line of Sindh Pakistan", Research Journal of Applied Sciences, Engineering and Technology, Vol. 10, No.4, pp. 393-400, 2015

[3] S. F. Khahro, K. Tabbasum, A. M. Soomro, X. Liao, M. B. Alvi, L. Dong, M. F. Manzoor, "Techno-economical evaluation of wind energy potential and analysis of power generation from wind at Gharo, Sindh Pakistan", Renewable and Sustainable Energy Reviews, Vol. 35, pp. 460-474, 2014

[4] K. Y. Lau, M. F. M. Yousof, S. N. M. Arshad, M. Anwari, A. H. M. Yatim, "Performance analysis of hybrid photovoltaic/diesel energy system under Malaysian conditions", Energy, Vol. 35, No. 8, pp. 32453255,2010

[5] M. S. Ngan, C. W. Tan, "Assessment of economic viability for $\mathrm{PV} /$ wind/diesel hybrid energy system in southern Peninsular Malaysia", Renewable and Sustainable Energy Reviews, Vol. 16, No. 1, pp. 634647,2012

[6] Global Wind Energy Council, Global Wind Report: Annual market update 2010, GWEC, 2011 
[7] M. H. Baloch, J. Wang, G. S. Kaloi, "A review of the state of the art control techniques for wind energy conversion system", International Journal of Renewable Energy Research, Vol. 6, No. 4, pp. 1276-1295, 2016

[8] M. H. Baloch, S. A. Abro, G. S. Kaloi, N. H. Mirjat, S. Tahir, M. Haroon Nadeem, M. Gul, Z. A. Memon, M. Kumar, "A research on electricity generation from wind corridors of Pakistan (two provinces): a technical proposal for remote zones", Sustainability, Vol. 9, No. 9, Article ID 1611, 2017

[9] M. H. Baloch, W. A. Wattoo, D. Kumar, G. S. Kaloi, A. A. Memon, S. Tahir, "Active and Reactive Power Control of a Variable Speed Wind Energy Conversion System based on Cage Generator", International Journal of Advance Computer Science and Applications, Vol. 8, No. 9, pp. 197-202, 2017

[10] A. Ghaffari, M. Krstic, S. Seshagiri, "Power optimization and control in wind energy conversion systems using extremum seeking", IEEE Transactions on Control Systems Technology, Vol. 22, No. 5, pp. 16841695,2014

[11] S. J. Johnson, C. P. van Dam, D. E. Berg, Active Load Control Techniques for Wind Turbines, Sandia National Laboratories, 2008

[12] S. P. Lakshman Rao, C. P. Kurian, B. K. Singh, A. Joythi V, "Simulation and control of DC/DC converter for MPPT based hybrid PV/Wind power system", International Journal of Renewable Energy Reasearch, Vol. 4, No. 3, pp. 801-809, 2014

[13] S. S. Mali, B. E. Kushare, "MPPT algorithms: Extracting maximum power from wind turbines", International Journal of Innovative Research in Electrical, Electronics, Instrumentation and Control Engineering, Vol. 1, No. 5, pp. 199-202, 2013

[14] W. M. Lin, C. M. Hong, F. S. Cheng, "Fuzzy neural network output maximization control for sensorless wind energy conversion system", Energy, Vol. 35, No. 2, pp. 592-601, 2010

[15] A. G. Abo-Khalil, D. C. Lee. "MPPT control of wind generation systems based on estimated wind speed using SVR", IEEE Transactions on Industrial Electronics, Vol. 55, No. 3, pp. 1489-1490, 2008

[16] S. Morimoto, H. Nakayama, M. Sanada, Y. Takeda, "Sensorless output maximization control for variable-speed wind generation system using IPMSG", IEEE Transactions on Industry Applications, Vol. 41, No. 1, pp. $60-67,2005$

[17] M. Kesraoui, N. Korichi, A. Belkadi. "Maximum power point tracker of wind energy conversion system", Renewable Energy, Vol. 36, No. 10, pp. 2655-2662, 2010

[18] M. Pucci, M. Cirrincione, "Neural MPPT control of wind generators with induction machines without speed sensors", IEEE Transactions on Industrial Electronics, Vol. 58, No. 1, pp. 37-47, 2011

[19] S. M. R. Kazmi, H. Goto, H. J. Guo, O. Ichinokura, “A novel algorithm for fast and efficient speed-sensorless maximum power point tracking in wind energy conversion systems", IEEE Transactions on Industrial Electronics, Vol. 58, No. 1, pp. 29-36, 2011

[20] P. M. Anderson, A. Bose, "Stability simulation of wind turbine systems", IEEE Transactions on Power Apparatus and Systems, Vol. 12, pp. 3791-3795, 1983

[21] M. H. Baloch, J. Wang, G. S. Kaloi, "Stability and nonlinear controller analysis of wind energy conversion system with random wind speed", International Journal of Electrical Power \& Energy Systems, Vol. 79, pp. 75-83, 2016

[22] M. H. Baloch, J. Wang, G. S. Kaloi, "A Point of View: Analysis and Investigation of Wind Power from Southern Region of Pakistan", International Journal on Energy Conversion, Vol. 3, No. 3, pp. 103-110, 2015

[23] M. Pucci, M. Cirrincione, "Neural MPPT control of wind generators with induction machines without speed sensors", IEEE Transactions on Industrial Electronics, Vol. 58, No. 1, pp. 37-47, 2011

[24] J. F. Manwell, J. G. McGowan, A. L. Rogers, Wind Energy Explained: Theory, Design and Applications, John Wiley \& Sons, 2010

[25] J. G. Slootweg, S. W. H. de Haan, H. Polinder, W. L. King, "General model for representing variable speed wind turbines in power system dynamics simulations", IEEE Transactions on Power Systems, Vol. 18, No. 1, pp. 144-151, 2003
[26] R. Cardenas, R. Pena, J. C. Clare, P. Wheeler, "Analytical and experimental evaluation of a WECS based on a cage induction generator fed by a matrix converter", IEEE Transactions on Energy Conversion, Vol. 26, No. 1, pp. 204-215, 2011

[27] R. L. Iglesias, R. L. Arantegui, M. A. Alonso, "Power electronics evolution in wind turbines-A market-based analysis", Renewable and Sustainable Energy Reviews, Vol. 15, No. 9, pp. 4982-4993, 2011

[28] J. A. Baroudi, V. Dinavahi, A. M. Knight, "A review of power converter topologies for wind generators", Renewable Energy, Vol. 32, No. 14, pp. 2369-2385, 2014

[29] Z. Chen, J. M. Guerrero, F. Blaabjerg, "A review of the state of the art of power electronics for wind turbines", IEEE Transactions on Power Electronics, Vol. 24, No. 8, pp. 1859-1875, 2009

[30] S. Li, T. A. Haskew, L. Xu, "Conventional and novel control designs for direct driven PMSG wind turbines", Electric Power Systems Research, Vol. 80, No. 3, pp. 328-338, 2010

[31] G. S. Kaloi, J. Wang, M. H. Baloch, "Dynamic Modeling and Control of DFIG for Wind Energy Conversion System Using Feedback Linearization", Journal of Electrical Engineering and Technology, Vol. 11, No. 5, pp. 1137-1146, 2016

[32] E. Koutroulis, K. Kalaitzakis, "Design of a maximum power tracking system for wind-energy-conversion applications", IEEE Transactions on Industrial Electronics, Vol. 53, No. 2, pp. 486-494, 2006 